\title{
Ethanol extract of Chrysanthemum zawadskii Herbich induces autophagy and apoptosis in mouse colon cancer cells through the regulation of reactive oxygen species
}

\author{
Kwang-Youn Kim¹, Tae-Woo Oh¹, Hye-Jin Yang ${ }^{1}$, Young-Woo Kim² ${ }^{2}$ Jin-Yeul Ma ${ }^{1}$ and Kwang-II Park ${ }^{*}$
}

\begin{abstract}
Background: Recent research has suggested that autophagy can provide a better mechanism for inducing cell death than current therapeutic strategies. This study investigated the effects of using an ethanol extract of Chrysanthemum zawadskii Herbich (ECZ) to induce apoptosis and autophagy associated with reliable signal pathways in mouse colon cancer CT-26 cells.

Methods: Using ECZ on mouse colon cancer CT-26 cells, cell viability, annexin V/propidium iodide staining, acridine orange staining, reactive oxygen species (ROS) and western blotting were assayed.

Results: ECZ exhibited cytotoxicity in CT-26 cells in a dose-dependent manner. ECZ induced apoptosis was confirmed by caspase-3 activation, poly (ADP-ribose) polymerase cleavage, and increased production of reactive oxygen species (ROS). Furthermore, it was shown that ECZ induced autophagy via the increased conversion of microtubule-associated protein 1 light chain 3ll, the degradation of p62, and the formation of acidic vesicular organelles. The inhibition of ROS production by N-Acetyl-L-cysteine resulted in reduced ECZ-induced apoptosis and autophagy. Furthermore, the inhibition of autophagy by 3-methyladenine resulted in enhanced ECZ-induced apoptosis via increased ROS generation.

Conclusion: These findings confirmed that ECZ induced ROS-mediated autophagy and apoptosis in colon cancer cells. Therefore, ECZ may serve as a novel potential chemotherapeutic candidate for colon cancer.
\end{abstract}

Keywords: Chrysanthemum zawadskii Herbich, Colon cancer, Apoptosis, Autophagy, Reactive oxygen species

\section{Background}

Colon cancer is the third most common cancer in men and the second most common cancer in women worldwide [1]. Early diagnosis with colonoscopy and the removal of precancerous lesions has resulted in a recent decline in the incidence of colon cancer in the United States; however, its incidence is increasing in Asia and Eastern Europe [2]. In Korea, despite the development of various treatment methods, colon cancer has now become

\footnotetext{
* Correspondence: kipark@kiom.re.kr.

${ }^{1}$ Korean Medicine (KM) Application Center, Korea Institute of Oriental

Medicine (KIOM), Daegu 41062, Republic of Korea

Full list of author information is available at the end of the article
}

the fourth leading cause of overall mortality, and its incidence is still increasing in both men and women.

Autophagy affects a wide range of processes, including homeostasis, developmental process, immune function, aging, and various cellular function [3]. Autophagy is a catabolic process which involves the degradation of the large protein complexes and dysfunctional organelles. These components are sequestered and transported to lysosomes for degradation as a cytoprotective mechanism [4]. Also, when cellular stress is extensive, autophagy acts degradation and recycling of process by the accumulation of acidic vesicular organelles (AVOs) through an alternative cell-death pathway as cytotoxic function

(c) The Author(s). 2019 Open Access This article is distributed under the terms of the Creative Commons Attribution 4.0 International License (http://creativecommons.org/licenses/by/4.0/), which permits unrestricted use, distribution, and reproduction in any medium, provided you give appropriate credit to the original author(s) and the source, provide a link to the Creative Commons license, and indicate if changes were made. The Creative Commons Public Domain Dedication waiver (http://creativecommons.org/publicdomain/zero/1.0/) applies to the data made available in this article, unless otherwise stated. 
$[5,6]$. Therefore, the dysfunction of autophagy can affect the incidence and treatment of diseases such as cancer [7]. Recent reports have proposed autophagy as a novel strategy for cancer therapy $[8,9]$. However, the action of autophagy in cancer is highly complex and affected by genetic differences $[10,11]$. When apoptosis is excessive or deficient in the spontaneous destruction pattern of cells, this can contribute to the growth and recurrence of ischemia, neurodegenerative disease, autoimmune disease, viral infection, and tumors $[2,12]$. Recently, the complex interactions between autophagy and apoptosis have received attention, with studies showing that apoptosis can sometimes act as an inhibitor or inducer of autophagy, thus resulting in changed resistance to many anticancer drugs or to a clinical application [13, 14]. Further studies are needed on the interaction between autophagy and apoptosis under various conditions [15].

Chrysanthemum zawadskii Herbich (CZ) is a perennial herb from the family Asteraceae, which is grown in countries including China, Russia, Mongolia, and Japan [16]. Extracts of CZ have been used in traditional medicine and as a tea in Korea and China. CZ has been shown to have effective therapeutic and medicinal properties, including antimicrobial, antioxidant, and antimycotic activity [17-19]. Linarin, one of its physiologically active agents, has been reported to exhibit antiinflammatory, antipyretic, hepatoprotective, antibacterial, anticancer, and antioxidant activity [20-22]. However, although the beneficial and pharmacological effects of $\mathrm{CZ}$ are established, the molecular mechanisms underlying its anticancer effects in colon cancer remain unknown. Therefore, the aim of the present study was to investigate the chemotherapeutic effects of an ethanol extract of CZ (ECZ) and to elucidate the interrelated mechanisms involving apoptosis and autophagy in mouse colon cancer CT-26 cells. The results showed that the production of reactive oxygen species (ROS) by ECZ may offer a therapeutic strategy to improve the treatment of colon cancer through the relationship between autophagy and apoptosis.

\section{Materials and methods}

\section{Reagents}

Chlorogenic acid and 3,5-di-caffeoylquinic acid were purchased from Sigma-Aldrich (St. Louis, MO, USA). Luteolin was obtained from Faces Biochemical Co., Ltd. (Wuhan, China). HPLC-grade acetonitrile was purchased from Thermo Fisher Scientific (Pittsburgh, PA, USA), and LC/MS-grade formic acid was purchased from SigmaAldrich. The ultrapure water used in the HPLC analysis was prepared using a Puris-Evo UP Water system with Evo-UP Dio VFT and Evo-ROP Dico20 (Mirae ST Co., Ltd., Anyang, Gyeonggi-do, Korea). Dulbecco's modified Eagle's medium (DMEM), penicillin/streptomycin and fetal bovine serum (FBS) were obtained from Hyclone
(Logan, UT, USA). Acridine orange (AO), dichlorodihydrofluorescein diacetate (DCF-DA), 3-methyladenine (3$\mathrm{MA}$ ), and N-Acetyl-L-cysteine (NAC) were purchased from Sigma-Aldrich. Cell counting kit (CCK)-8 assays and FITC Annexin V-Apoptosis Detection Kit were obtained from Dojindo Molecular Technologies, Inc. (Rockville, MD, USA) and BD Biosciences (San Jose, CA, USA), respectively. Primary antibodies against Bax, Bcl-2, caspase 3 , poly (ADP-ribose) polymerase (PARP), microtubuleassociated protein 1 light chain-3B (LC3B), p62/SQSTM1, and $\beta$-actin were purchased from Cell Signaling Technology (Danvers, MA, USA), and Santa Cruz Biotechnology (Santa Cruz, CA, USA), respectively. The antimouse IgG and goat antirabbit secondary antibodies were purchased from Enzo Life Science (Farmingdale, NY, USA).

\section{Preparation of standard solutions and ECZ}

Standard stock solutions in methanol $(1 \mathrm{mg} / \mathrm{ml})$ of chlorogenic acid, 3,5-di-caffeoylquinic acid, and luteolin were prepared. The standards were mixed from the stock solutions, and then freshly prepared by serial dilution in methanol to plot the calibration curves. The final concentrations of the calibration samples were in the range 25$400 \mu \mathrm{g} / \mathrm{ml}$ for chlorogenic acid and 3,5-di-caffeoylquinic acid, and $1.25-20.00 \mu \mathrm{g} / \mathrm{ml}$ for luteolin. $\mathrm{CZ}$ was purchased from Yeongcheon Oriental Herbal Market (Yeongcheon, Korea) and was authenticated by Professor Ki Hwan Bae, a medical botanist at the College of Pharmacy, Chungnam National University, Republic of Korea. A voucher (No. 203) was deposited at the Korean Medicine Application Center Korea Institute of Oriental Medicine in Daegu, Republic of Korea. Dried CZ (30 g) was ground to a fine powder, added to $300 \mathrm{ml}$ of $70 \%$ ethanol, and then extracted by shaking it in an incubator at $100 \mathrm{rpm}$ for $24 \mathrm{~h}$ at $40{ }^{\circ} \mathrm{C}$. The extract was then filtered through a $150 \mu \mathrm{m}$ testing sieve (Retsch, Haan, Germany), evaporated, concentrated through lyophilization, and then stored at $20^{\circ} \mathrm{C}$ (yield 13.83\%). For the experiments, ECZ powder (10 mg) was dissolved in $1 \mathrm{ml}$ of deionized distilled water $(\mathrm{v} / \mathrm{v})$ and filtered through a $0.22 \mu \mathrm{m}$ disk filter.

\section{High performance liquid chromatography (HPLC) analysis} The three components in ECZ were identified and quantified by HPLC via a previously reported method [23, 24]. In this study, the HPLC analysis was performed using a Dionex UltiMate 3000 system (Dionex Corp., Sunnyvale, CA, USA) equipped with a binary pump, an auto-sampler, a column oven and a diode array UV/Vis detector (DAD). System control and data analysis were performed using Dionex Chromelon software. The three components were eluted in a gradient system based on $0.1 \%$ formic acid in deionized water (solvent A) and acetonitrile (solvent B). To improve the chromatographic separation capacity, the gradient elution system was programmed as follows: 5- 
$12 \% \mathrm{~B}, 0-5 \mathrm{~min} ; 12-15 \% \mathrm{~B}, 5-7 \mathrm{~min} ; 15 \% \mathrm{~B}, 7-12 \mathrm{~min}$; $15-20 \%$ B, $12-14$ min; 20\% B, 14-20 min; 20-60\% B, 20$35 \mathrm{~min}$; $60-90 \% \mathrm{~B}, 35-40 \mathrm{~min} ; 90 \% \mathrm{~B}, 40-45 \mathrm{~min}$; $90-$ $95 \% \mathrm{~B}, 45-46 \mathrm{~min} ; 5 \% \mathrm{~B}, 46-60 \mathrm{~min}$ at a flow rate of 1.0 $\mathrm{ml} / \mathrm{min}$. The components were separated on a Xbridge C18 column $(250 \times 4.60 \mathrm{~mm}, 5 \mu \mathrm{m}$; Waters, Milford, MA, USA), and the column oven temperature was kept at $40{ }^{\circ} \mathrm{C}$. The injection volume was $5 \mu \mathrm{l}$. The detection wavelengths for the three components were set at 220, 254, 320 and $365 \mathrm{~nm}$.

\section{Cell culture}

The mouse colon cancer CT-26 and human colon cancer HT-29 cell lines were obtained from American Type Culture Collection (Manassas, VA, USA). The cells were cultured using DMEM containing 10\% FBS, 100 units/ml

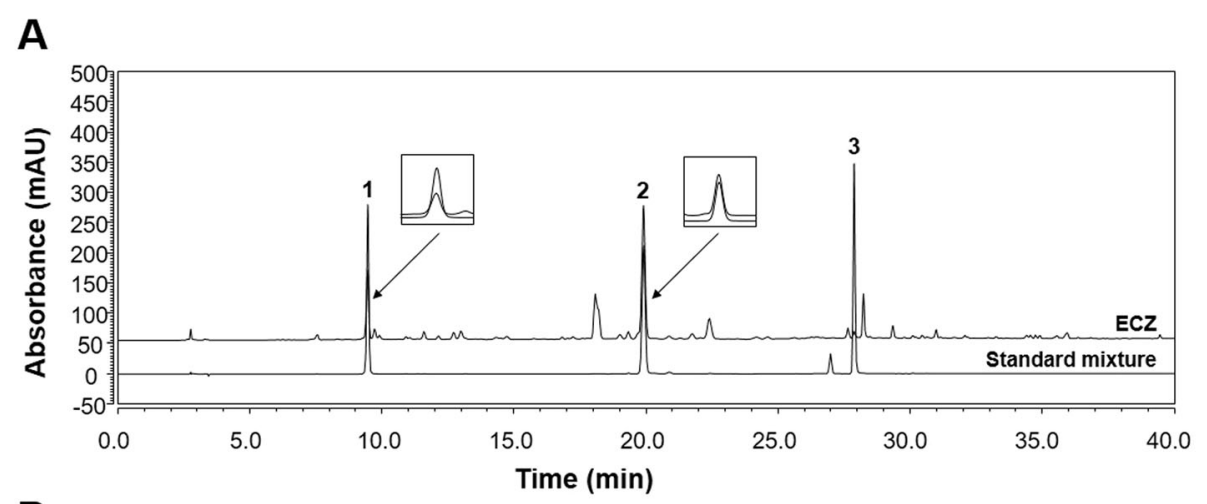

B

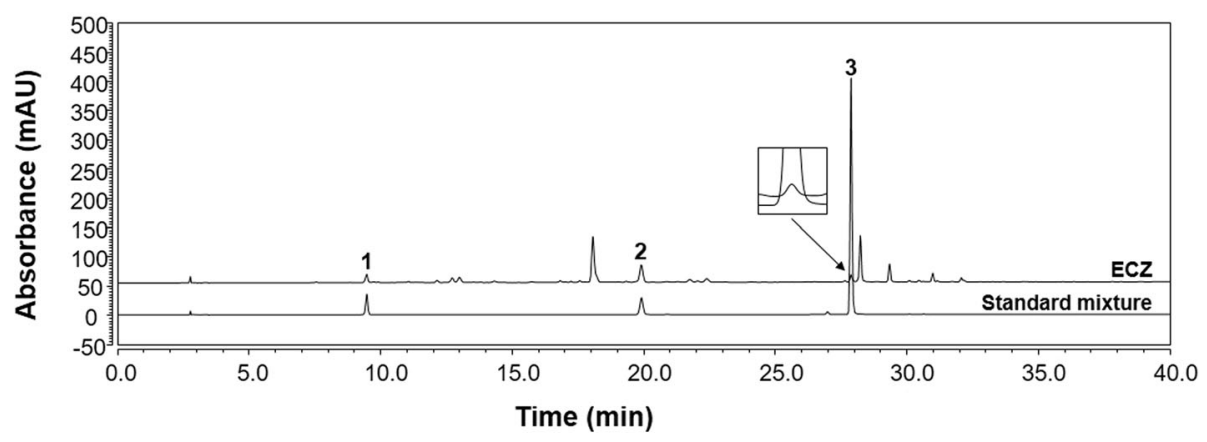

C<smiles>O=C(/C=C/c1ccc(O)c(O)c1)O[C@H]1C[C@@](O)(C(=O)O)C[C@H](O)[C@H]1O</smiles>

(1) Chlorogenic acid<smiles>O=C(/C=C/c1ccc(O)c(O)c1)OC1CC(O)(C(=O)O)CC(OC(O)/C=C/c2ccc(O)c(O)c2)C1O</smiles>

(2) 3,5-Di-caffeoylquinic acid<smiles>O=c1cc(-c2ccc(O)c(O)c2)oc2cc(O)cc(O)c12</smiles>

(3) Luteolin

Fig. 1 High-performance liquid chromatography (HPLC) chromatograms of ethanol extracts of Chrysanthemum zawadskii Herbich (ECZ) and the chemical structures of three markers. For ECZ, the markers were identified at wavelengths of (a) 320 and (b) $365 \mathrm{~nm}$ by using HPLC and a diode array UVNis detector. c The chemical structures of three markers of ECZ. (1) chlorogenic acid, (2) 3,5-di-caffeoylquinic acid, and (3) luteolin 
Table 1 Calibration curves of three analytes using HPLC-DAD

\begin{tabular}{lllll}
\hline No. & Components & Linear range $(\mu \mathrm{g} / \mathrm{mL})$ & Regression Equation ${ }^{\mathrm{a})}$ & $\begin{array}{l}\text { Correlation } \\
\text { coefficient }\left(R^{2}\right)\end{array}$ \\
\hline 1 & & $25.00-400.00$ & $y=0.2428 x+1.9062$ & 0.9997 \\
2 & Chlorogenic acid & $25.00-400.00$ & $y=0.2843 x-1.6878$ & 0.9999 \\
3 & 3,5-Di-caffeoylquinic acid & $1.25-20.00$ & $y=0.3257 x+0.0543$ & 0.9999 \\
\hline
\end{tabular}

a) y: peak area, $x$ : concentration $(\mu \mathrm{g} / \mathrm{mL})$

b) Regression coefficient $(n=3)$

penicillin and $100 \mu \mathrm{g} / \mathrm{ml}$ streptomycin at $37^{\circ} \mathrm{C}$ in a humidified atmosphere with $5 \% \mathrm{CO}_{2}$.

\section{Cell viability}

The cytotoxicity of ELT on CT-26 cells was calculated using CCK- 8 assay. The cells were seeded at $1 \times 10^{4}$ cells/ well in a 96-well plate. After incubation for $24 \mathrm{~h}$, the cells in each well were treated with ELT at specific concentrations for $24 \mathrm{~h}$. A CCK-8 assay was then performed in accordance with the manufacturer's instructions. Absorbance was determined at $450 \mathrm{~nm}$ on a VERSAmax microplate reader (Molecular Devices, Sunnyvale, CA, USA). Cell viability was calculated relative to untreated controls as follows: viability $(\%$ control $)=100 \times$ absorbance of treated sample/absorbance of control.

\section{Annexin V/propidium iodide (PI) assay}

To verify the induction of apoptosis, CT-26 and HT-29 cells were cultured at a density of $1 \times 10^{4}$ cells and treated with ECZ for $24 \mathrm{~h}$. The cells were then collected and double stained with Annexin-V-FITC and PI (BD Biosciences), following the manufacturer's instructions. Apoptotic cells were determined by flow cytometry (Becton Dickinson Co.) and the percentages of apoptotic cells were calculated using Cell Quest software (Becton Dickinson Co.).

\section{Detection of acidic vesicular organelles}

To quantify the number of AVOs, CT-26 and HT-29 cells were cultured at a density of $1 \times 10^{4}$ cells/well in 6well plates. After treatment with ECZ for $24 \mathrm{~h}$, the cells were stained with $\mathrm{AO}(1 \mu \mathrm{g} / \mathrm{ml})$ at $37^{\circ} \mathrm{C}$ for $20 \mathrm{~min}$ in the dark. The cells were then washed with PBS, analyzed by a flow cytometry (Becton Dickinson Co.), and quantified using Cell Quest software (Becton Dickinson Co.).

\section{Measurement of intracellular ROS generation}

To determine intracellular ROS production, CT-26 cells were cultured in 6 -well plates at a density of $1 \times 10^{4}$

Table 2 The amounts of three analytes in ECZ using HPLC-DAD

\begin{tabular}{lllllll}
\hline No. & Components & $t_{R}$ & $\mu \mathrm{g} / \mathrm{mL}$ & $\mu \mathrm{g} / \mathrm{mg}$ & $\mathrm{SD}$ & $\mathrm{RSD}, \%$ \\
\hline 1 & Chlorogenic acid & 9.46 & 38.13 & 3.81 & 0.22 & 1.96 \\
2 & 3,5-Di-caffeoylquinic acid & 19.89 & 99.43 & 9.94 & 0.78 & 2.43 \\
3 & Luteolin & 27.87 & 3.38 & 0.34 & 0.02 & 1.96 \\
\hline
\end{tabular}

cells/well. The cells were treated with ECZ and incubated with DCFH-DA $(10 \mu \mathrm{M})$ at $37^{\circ} \mathrm{C}$ for $30 \mathrm{~min}$ and then washed twice with PBS. For each experiment, the cells were analyzed by flow cytometry (Becton Dickinson Co.), and quantified using Cell Quest software (Becton Dickinson Co).

\section{Western blotting}

Cell extracts were prepared by incubating in lysis buffer [150 mM NaCl, $10 \mathrm{mM}$ Tris (pH 7.4), $5 \mathrm{mM}$ EDTA (pH 8.0), 1\% Triton X-100, $1 \mathrm{mM}$ PMSF, $20 \mu \mathrm{g} / \mathrm{ml}$ aprotinin, $50 \mu \mathrm{g} / \mathrm{ml}$ leupeptin, $1 \mathrm{mM}$ benzidine, and $1 \mathrm{mg} / \mathrm{ml}$ pepstatin]. For separation using sodium dodecyl sulfate-polyacrylamide gel electrophoresis, $50 \mu \mathrm{g}$ of proteins were loaded onto $12-15 \%$ gel and transferred to a polyvinylidene fluoride membrane. After blocking with TBS-T buffer [20 mM Tris (pH 7.4), $150 \mathrm{mM} \mathrm{NaCl}$, and $0.1 \%$ Tween 20] containing $5 \%$ skim milk, the membranes were incubated with primary and secondary antibodies, separately. The membranes were then washed with TBS-T buffer and visualized with ECL Western blotting detection reagents. The density of each band was determined with a fluorescence scanner (LAS 3000, Fuji Film) and analyzed with Multi Gauge V3.0 software.

\section{Statistical analysis}

Experiments were repeated to obtain three sets of consistent results. Unless otherwise stated, data are expressed as the mean \pm standard deviation of the mean. ANOVA was used to compare experimental and control values. Comparisons between multiple groups were performed using Tukey's multiple comparison tests, with the results considered statistically significant at ${ }^{* * *} p<0.001$.

\section{Results}

\section{HPLC analysis of ECZ}

The HPLC chromatograms for ECZ and a mix of the three standard components are shown in Fig. 1. The peaks for the three components in ECZ were identified by comparing their retention times, ultraviolet (UV) spectra, and chromatogram patterns with those of the standard mix. The target components were well separated and showed good selectivity, with no interference from other components within $40 \mathrm{~min}$. The retention times of the compounds in the chromatogram of the standard mix were 9.45 


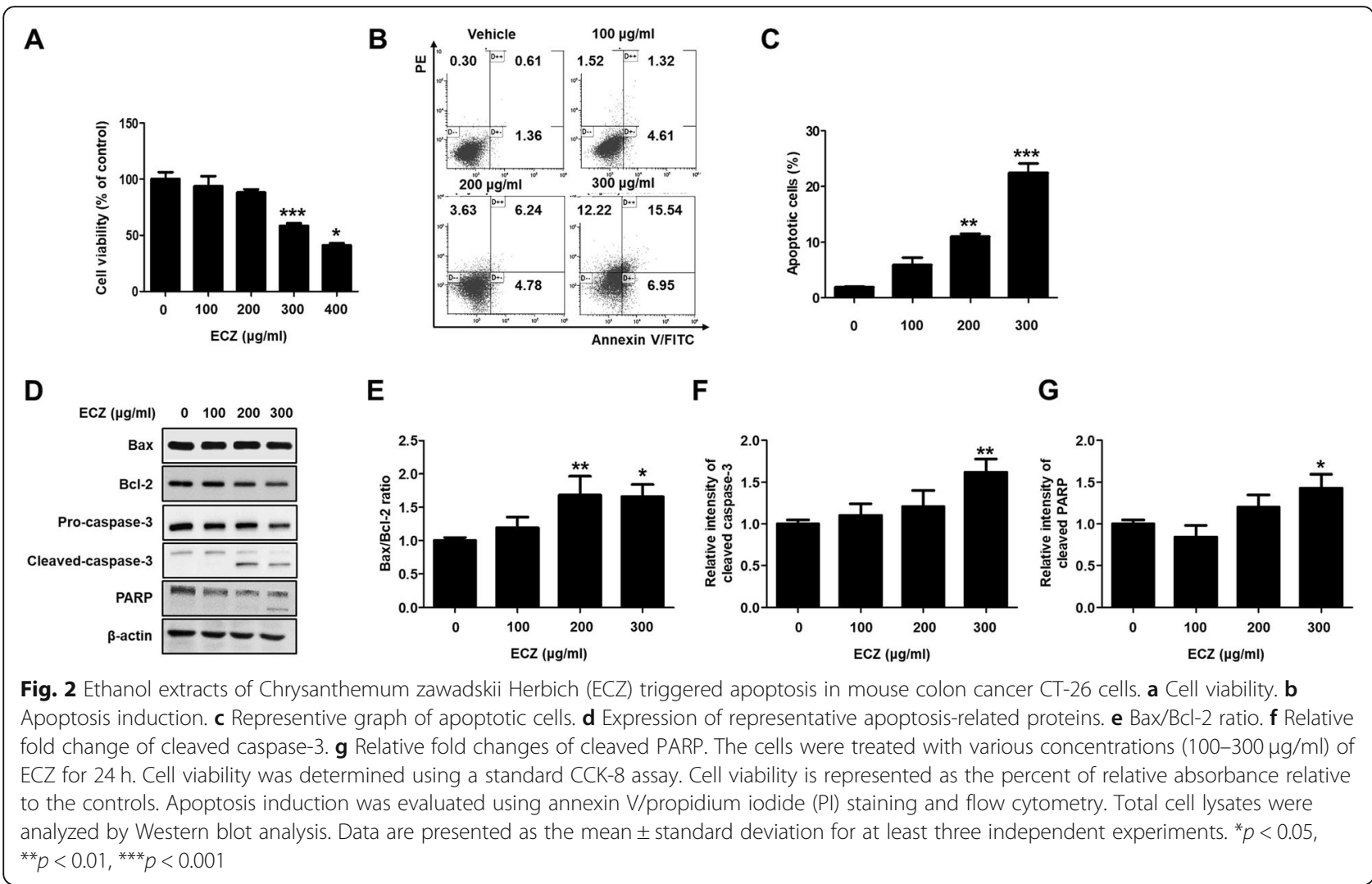

(chlorogenic acid), 19.89 (3,5-di-caffeoylquinic acid), and $27.86 \mathrm{~min}$ (luteolin). Under the same conditions, the retention times of the observed three components in ECZ were $9.46 \mathrm{~min}(1), 19.89 \mathrm{~min}$ (2), and $27.87 \mathrm{~min}$ (3), respectively. The UV wavelength for the HPLC was optimized according to the UV spectrum and maximum absorption for each standard component; the wavelength was set at $320 \mathrm{~nm}$ for detecting the first two components and $365 \mathrm{~nm}$ for detecting the third. Five different concentrations of the standard solutions for calibration were analyzed in triplicate. The calibration curve for the quantitative analysis was obtained by plotting the concentration of each component versus the peak area; this showed good linearity $\left(r^{2} \geq 0.9997\right)$ (Table 1). The amounts of the three components in ECZ were analyzed by applying regression equations calculated from the calibration curves. The results of the quantitative analysis are summarized in Table 2.

\section{ECZ inhibited proliferation and triggered apoptosis in mouse colon cancer CT-26 cells}

We examined the impact on cell viability of mouse colon cancer CT-26 cells to ECZ. Exposure significantly reduced the viability of CT-26 cells in a dose-dependent manner (Fig. 2a). To examine the anticancer effects of ECZ in CT26 cells, we quantitatively verified apoptosis by using Annexin V-FITC/propidium iodide (PI) staining. After treatment with 200 and $300 \mu \mathrm{g} / \mathrm{ml}$ of ECZ for $24 \mathrm{~h}$, flow cytometry analysis showed significantly increased in early and late apoptotic CT-26 cells from $2.02 \%$ to 10.30 and $15.05 \%$, respectively (Fig. $2 \mathrm{~b}$ and c). Addition, we confirmed that ECZ treatments also induced apoptosis in HT29 cells (Additional file 1: Fig. S1A). To investigate the mechanism for ECZ-induced apoptosis in CT-26 cells, the expression levels of apoptosis-related proteins were evaluated by western blot analysis. ECZ exposure did not affect the expression of Bax, but reduced the expression of $\mathrm{Bcl}-2$, and Bcl-2/Bax ratio was significantly reduced (Fig. $2 \mathrm{~d}$ and e). Furthermore, ECZ reduced the pro-form of caspase-3 and increasingly induced the cleavage of capspase- 3 and PARP in a dose-dependent manner (Fig. $2 \mathrm{~d}, \mathrm{f}$ and $\mathrm{g}$ ). These results indicated that ECZ-induced apoptosis was functionally associated with caspase-3 dependent pathways.

\section{ECZ induced autophagy in CT-26 cells}

We confirmed the effects of ECZ regarding the induction of autophagy by using AO staining. After treatment with 200 and $300 \mu \mathrm{g} / \mathrm{ml}$ of ECZ for $24 \mathrm{~h}$, there were significantly increases in the accumulation of acidic vesicular organelles (AVOs) from 9.04 to $16.08 \%$ and $18.72 \%$, respectively (Fig. $3 \mathrm{a}$ and b). Addition, we confirmed that ECZ treatments also induced autophagy in HT-29 cells (Additional file 1: Figure S1B). Furthermore, there were clear dose-dependent increased in the expression levels of LC3 conversion forms and p62/SQSTM1 (which are 


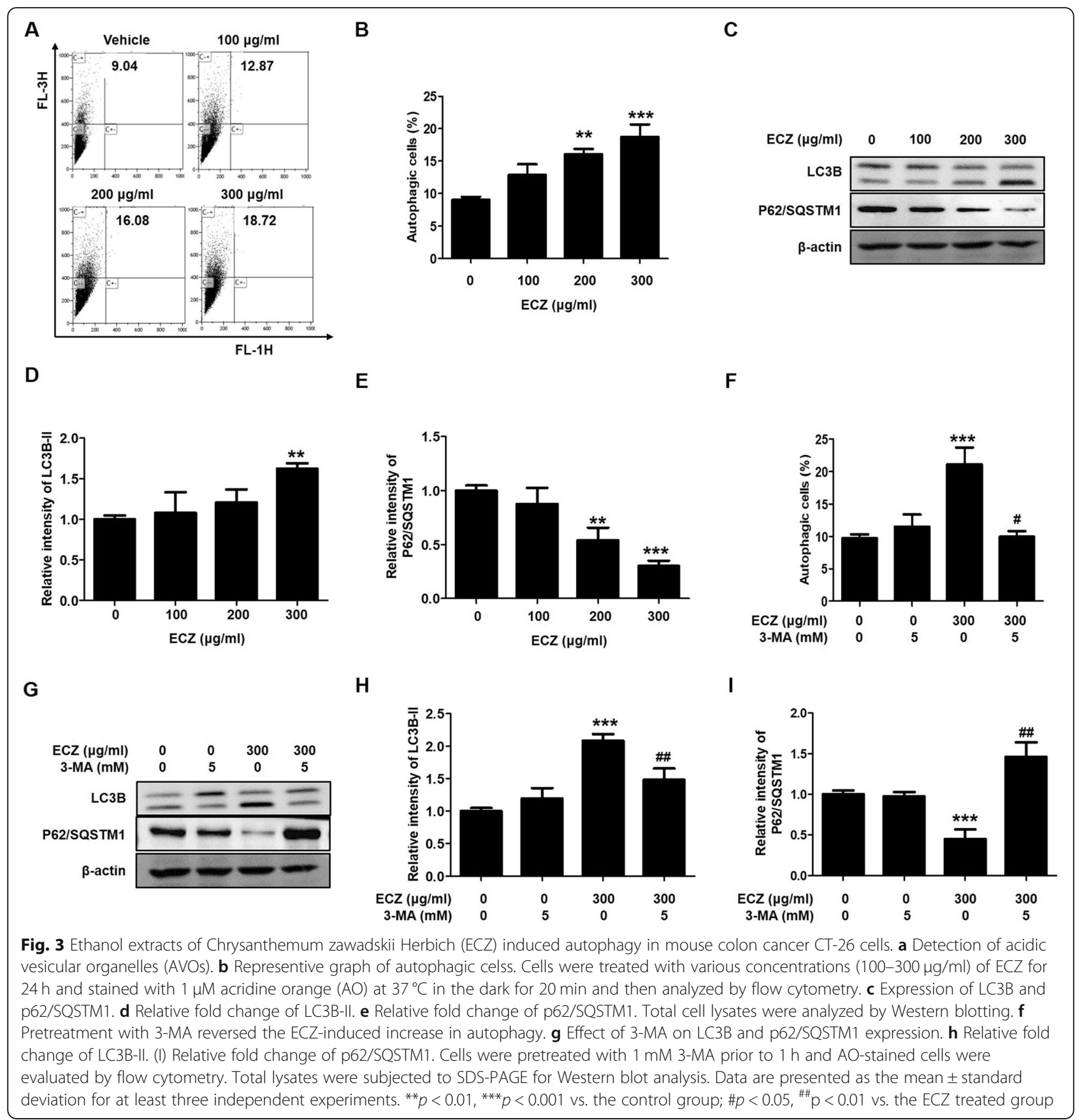

autophagy-specific markers) in ECZ-treated CT-26 cells (Fig. 3c, d and e). To reconfirm the ECZ-induced autophagy, we evaluated the formations of AVOs and the expression levels of LC3 conversion forms and p62/ SQSTM1 by using the autophagy inhibitor 3-MA. The levels of formation of AVOs in the presence or absence of 3-MA; were 9.97 or $21.13 \%$, respectively (Fig. 3f). Furthermore, the expression of LC3 conversion forms and p62/SQSTM1 significantly reverted when ECZ was combined with 3-MA compared with ECZ alone (Fig. 3g, h and i). These results indicated that ECZ induced autophagy by increasing autophagosome formations in CT-26 cells.

ECZ-induced apoptosis and autophagy were regulated by ROS production in CT-26 cells

Several recent studies have demonstrated that ROS plays an important role in the induction of apoptosis and autophagy $[25,26]$. Thus, we used flow cytometry with DCF-DA staining to examine whether there was a relationship between ROS production and ECZ-induced apoptosis and autophagy in CT-26 cells. ROS production 


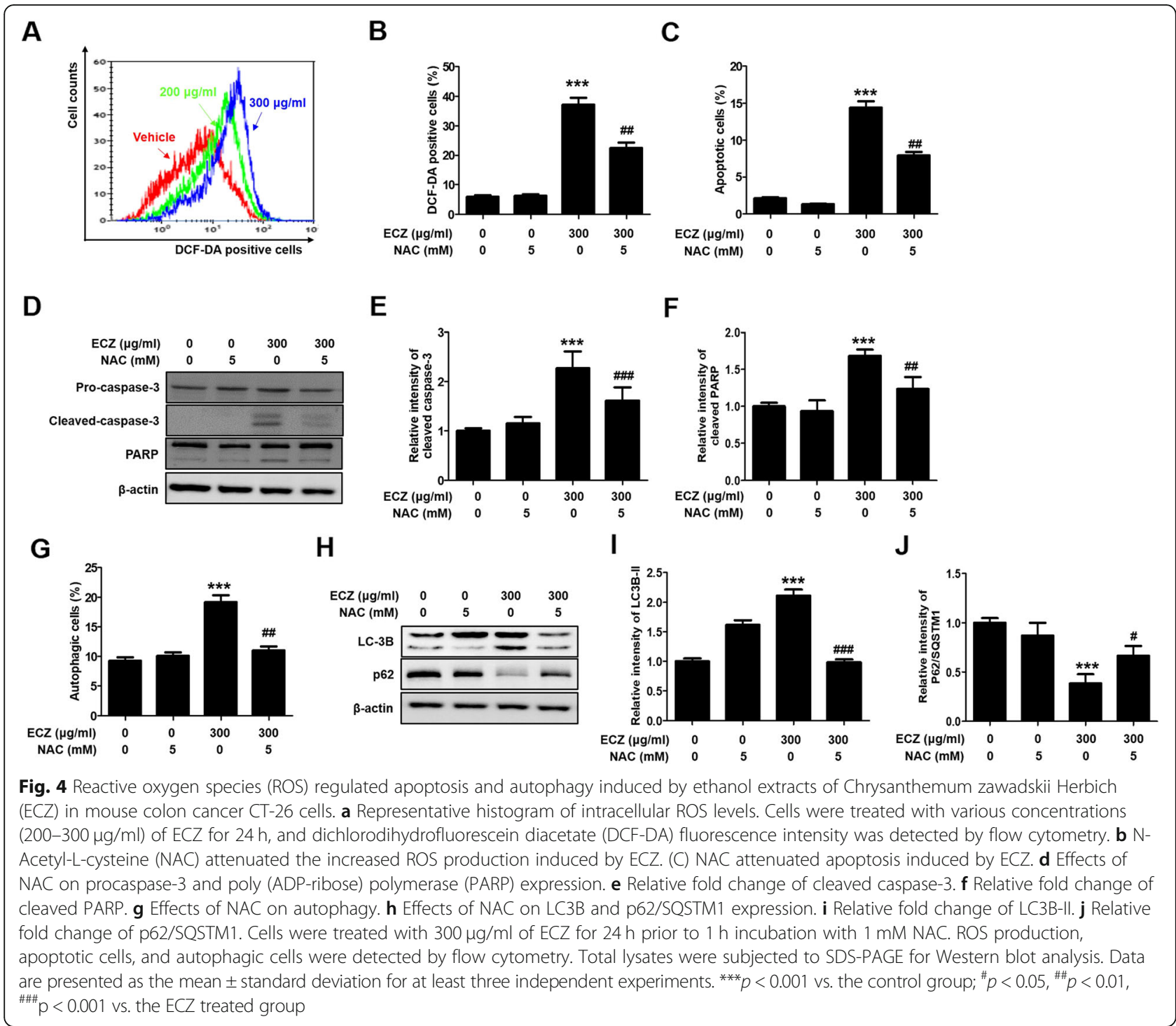

was significantly increased in a dose-dependent manner (Fig. 4a); this was reversed by pretreatment with NAC, which is a ROS scavenger (Fig. 4b). We then examined the effects of NAC on the crosstalk of ROS production between ECZ-induced apoptosis and autophagy. Pretreatment with NAC reduced both apoptotic cells and autophagic cells in CT-26 cells (Fig. 4c and g). Addition, we confirmed that pretreatment with NAC reduced both apoptotic cells and autophagic cells in HT-29 cells (Additional file 1: Figure S1C and 1D). Consistent with the flow cytometry results, NAC reversed the increased expression of procaspase-3, PARP, LC3 conversion, and p62/SQSTM1 (Fig. 4d, e, $f, h, i$ and $j$ ). These results indicated that ROS played a critical role not only in ECZ-triggered apoptosis via caspase-dependent pathways but also in autophagy via LC3-II expression and AVOs accumulation.
Inhibition of autophagy-enhanced ECZ-induced apoptosis via increased ROS production in CT-26 cells

To establish whether the inhibition of autophagy affected ECZ-induced apoptosis in CT-26 cells, we used flow cytometry with annexin-V-FITC staining after pretreatment with 3-MA to evaluate the induction of apoptosis. There was a greater increased in apoptotic cells among cells treated with a combination of ECZ and 3-MA than in cells treated with ECZ alone in CT-26 cells (Fig. 5a). Addition, we confirmed that pretreatment with 3-MA decreased ECZ-induced autophagy, but increased ECZ-induced apoptotic cells in HT-29 cells (Additional file 2: Figure S2A and S2B). Furthermore, there were greater increases in cleavage forms of caspase- 3 and PARP proteins with the combination ECZ and 3-MA than with ECZ alone, thus indicating that the induction of apoptosis was further enhanced when autophagy was blocked with 3-MA (Fig. 5a-d). Thereafter, 


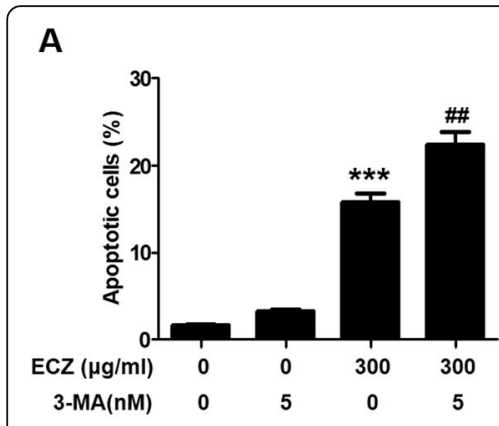

D
B

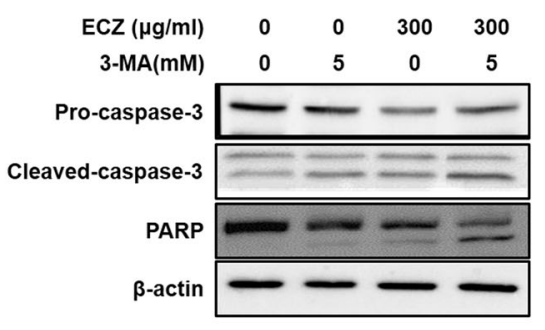

C

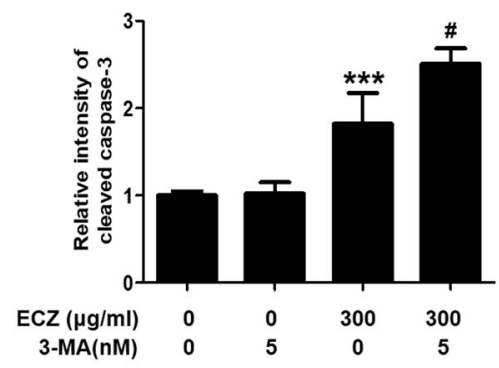

E
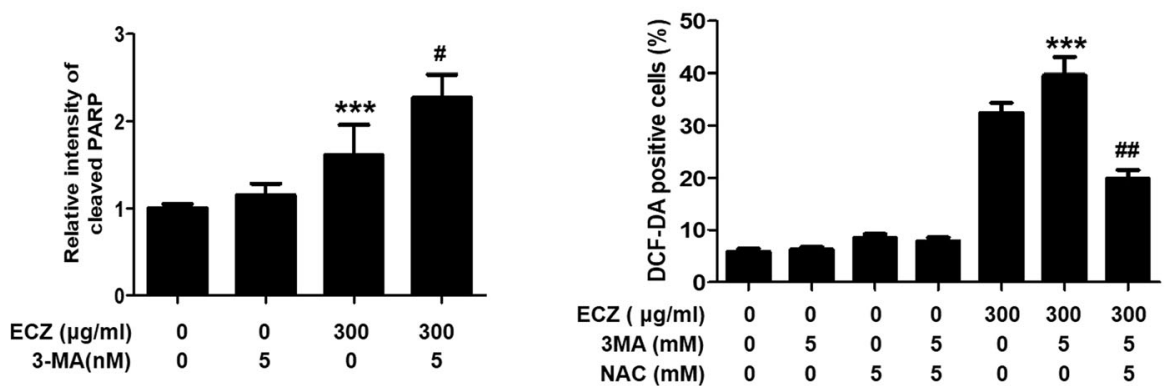

Fig. 5 Inhibition of autophagy enhanced apoptosis induced by ethanol extracts of Chrysanthemum zawadskii Herbich (ECZ) by increasing the production of reactive oxygen species (ROS) in mouse colon cancer CT-26 cells. a Treatment with 3-methyladenine (3-MA) enhanced ECZinduced apoptosis. $\mathbf{b}$ Effects of 3-MA treatment on caspase-3 and poly (ADP-ribose) polymerase (PARP) expression. $\mathbf{c}$ Relative fold change of cleaved caspase-3. d Relative fold change of PARP. Cells were pretreated with $5 \mathrm{mM}$ 3-MA prior to $1 \mathrm{~h}$. Apoptotic cells were evaluated by flow cytometry, and the proteins were detected by Western blot analysis. e Effects of 3-MA on ROS production. Cells were treated with $300 \mathrm{\mu g} / \mathrm{ml} \mathrm{ECZ}$

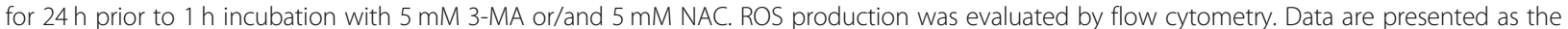
mean \pm standard deviation for at least three independent experiments. ${ }^{* *} p<0.001$ vs. the control group, $\# p<0.05,{ }^{\# \#} p<0.01$ vs. the ECZ treated group

to evaluate whether the inhibition of autophagy affected the production of ROS, we analyzed ROS levels in CT-26 cells after treatment with ECZ and 3-MA. ROS production was significantly increased in cells treated with the combination of ECZ and 3-MA compared with those treated with ECZ alone (Fig. 5e), and this increase in ROS production was clearly attenuated by treatment with NAC (Fig. 5e). These results indicated that autophagy played a protective role against the induction of apoptosis in CT26 cells by ECZ and that increasing ROS production by inhibiting autophagy enhanced the induction of apoptosis, consistent with the results in Fig. 5a.

\section{Discussion}

CZ has been reported to have diverse effects on several diseases, including pneumonia, bronchitis, coughs, colds, pharyngitis, bladder disease, hypertension, liver disease, and gastrointestinal disorders [27-29]. However, the molecular mechanisms underlying ECZ's anticancer effects are not yet understood. The aim of this study was to investigate the mechanism underlying the induction by ECZ of apoptosis and autophagy in mouse colon cancer CT-26 cells. The results showed that ECZ significantly inhibited cell viability in a dose-dependent manner in CT-26 cells. Furthermore,
ECZ clearly increased both apoptosis and autophagy via caspase-dependent pathways and AVOs formation in CT26 cells, respectively. Addition, ECZ induced ROSmediated apoptosis and autophagy human colon cancer HT-29 cells. Recent findings have suggested that autophagy as a cytoprotective mechanism is closely associated with resistance to apoptosis $[8,30]$. In the present study, the inhibition of autophagy by 3-MA enhanced ECZ-induced apoptosis in CT-26 and HT-29 cells. These results showed that autophagy plays a protective role against cytotoxic effects in colon cancer cells via the inhibition of apoptosis.

Many reports have shown that apoptosis and autophagy induction share a common mechanism associated with ROS production [12, 31]. Commonly, ROS play important roles in apoptosis and autophagy signaling and ROS production selectively induces cancer cell death [32]. An autophagy has dual roles to regulate the cell fate in cancer, where autophagy and apoptosis share the crosstalk survival and/or death signal pathway in many cancer cells [32-34]. Other study demonstrated that cross link between autophagy and apoptosis are associated with inhibit cancer cell death by autophagy inhibitors and antioxidants using potentiate or restore the cytotoxicity effect of the drug $[35,36]$. Consistent with these previous reports, 
the present study showed that ECZ-induced apoptosis and autophagy in CT-26 cells were significantly reversed by pretreatment with the ROS scavenger NAC. Treatment with NAC also restored the expression of the apoptosisand autophagy-related proteins procaspase-3 and LC3. Furthermore, the inhibition of autophagy enhanced ECZinduced apoptosis in CT-26 cells, and this was further enhanced by ROS production following treatment with 3MA. These results demonstrated that intracellular ROS production plays a critical role during ECZ-induced apoptosis and autophagy and that increasing ROS generation by the inhibition of autophagy results in enhanced apoptosis.

\section{Conclusion}

The results of this study showed that ECZ induced apoptosis in mouse colon cancer CT-26 cells via caspasedependent pathways and that it triggered autophagy via an increase in the formation of autophagosomes. In particular, we showed that ROS production played a role in ECZinduced apoptosis and autophagy. The inhibition of autophagy enhanced ECZ-induced apoptosis resulting from increased ROS production, thus suggesting that autophagy may play a cytoprotective role via apoptosis resistance. Therefore, we believe that ECZ can be used for cancer chemoprevention or as a chemotherapeutic agent; however, further studies are needed to explore the molecular mechanisms and evaluate the anticancer activity of ECZ in vivo.

\section{Supplementary information}

Supplementary information accompanies this paper at https://doi.org/10. 1186/s12906-019-2688-0.

\begin{abstract}
Additional file 1: Figure S1. Ethanol extracts of Chrysanthemum zawadskii Herbich (ECZ) induced reactive oxygen species (ROS)-mediated apoptosis and autophagy in human colon cancer HT-29 cells. (A) Apoptosis induction. (B) N-Acetyl-L-cysteine (NAC) attenuated apoptosis induced by ECZ. (C) Detection of acidic vesicular organelles (AVOs). (D) Effects of NAC on autophagy. Cells were treated with various concentrations $(100-300 \mu \mathrm{g} / \mathrm{ml})$ of ECZ for $24 \mathrm{~h}$ and stained with annexin V/propidium iodide and $1 \mu \mathrm{M}$ acridine orange (AO) at $37^{\circ} \mathrm{C}$ in the dark for 20 min and then analyzed by flow cytometry. Cells were pretreated with 1 mM NAC prior to $1 \mathrm{~h}$ and annexin V/propidium iodide and $\mathrm{AO}$-stained cells were evaluated by flow cytometry. Data are presented as the mean \pm standard deviation for at least three independent experiments. ${ }^{* * *} p<0.001$ vs. the control group; ${ }^{\# \#} \mathrm{p}<0.001$ vs. the ECZ treated group.

Additional file 2: Figure S2. Inhibition of autophagy enhanced apoptosis induced by ethanol extracts of Chrysanthemum zawadskii Herbich (ECZ) in human colon cancer HT-29 cells. (A) Pretreatment with 3-methyladenine (3-MA) reversed the ECZ-induced increase in autophagy. (B) Treatment with 3-MA enhanced ECZ-induced apoptosis. Cells were pretreated with $5 \mathrm{mM}$ 3-MA prior to $1 \mathrm{~h}$. Apoptotic and autophagic cells were evaluated by flow cytometry. Data are presented as the mean \pm standard deviation for at least three independent experiments. ${ }^{* *} \mathrm{p}<$ 0.001 vs. the control group; \#\#\#<0.001 vs. the ECZ treated group.
\end{abstract}

\section{Abbreviations}

3-MA: 3-methyladenine; AO: acridine orange; ATCC: American Type Culture Collection.; AVOs: acidic vesicular organelles; CCK-8: cell counting kit-8; CZ: Chrysanthemum zawadskii Herbich; DCF-DA: dichlorodihydrofluorescein diacetate; DMEM: Dulbecco's modified Eagle's medium; ECZ: ethanol extracts of Chrysanthemum zawadskii Herbich; FBS: fetal bovine serum; HPLC: High performance liquid chromatography; LC-3B: microtubule-associated protein 1 light chain-3B; NAC: N-acetyl-L-cysteine; PARP: poly (ADP-ribose) polymerase; PI: propidium iodide; ROS: reactive oxygen species

\section{Authors' contributions}

KYK conducted research and experiments, designed research and wrote the paper. TWO and YWK conducted research and experiments. HJY performed the High-performance liquid chromatography (HPLC) analysis. JYM and KIP reviewed the literature, revised the manuscript and coordinated the study. KIP supported financial funding. All authors read and approved the final manuscript.

\section{Funding}

This work was supported by a grant (No. KSN1812102) from the Korea Institute of Oriental Medicine funded by the Ministry of Education, Science and Technology (MEST), Republic of Korea. This work was also supported by Basic Science Research Program through the National Research Foundation of Korea (NRF) funded by the Ministry of Education (NRF-

2017R1D1A1B03032284) and by grant (No. 20190055) funded by the Ministry of Oceans and Fisheries, Republic of Korea.

\section{Availability of data and materials}

The datasets for supporting the outcomes of the study are included in the article. However, additional information can be provided on request made to the corresponding author.

Ethics approval and consent to participate

Not applicable.

\section{Consent for publication}

Not applicable.

\section{Competing interests}

The authors declare that they have no competing interests.

\section{Author details}

${ }^{1}$ Korean Medicine (KM) Application Center, Korea Institute of Oriental Medicine (KIOM), Daegu 41062, Republic of Korea. ${ }^{2}$ Department of Herbal Formula, Medical Research Center (MRC-GHF), College of Oriental Medicine, Daegu Haany University, Gyeongsan 38610, Republic of Korea.

Received: 5 June 2018 Accepted: 20 September 2019

Published online: 21 October 2019

\section{References}

1. Jemal A, Center MM, DeSantis C, Ward EM. Global patterns of cancer incidence and mortality rates and trends. Cancer Epidemiol Biomark Prev. 2010;19(8):1893-907.

2. Jeong SY, Seol DW. The role of mitochondria in apoptosis. BMB Rep. 2008; 41(1):11-22.

3. Valdor R, Macian F. Autophagy and the regulation of the immune response. Pharmacol Res. 2012;66(6):475-83.

4. Ohsumi Y. Historical landmarks of autophagy research. Cell Res. 2014:24(1):9-23.

5. Yang Z, Klionsky DJ. Eaten alive: a history of macroautophagy. Nat Cell Biol. 2010;12(9):814-22.

6. Liu Y, Levine B. Autosis and autophagic cell death: the dark side of autophagy. Cell Death Differ. 2015;22(3):367-76.

7. Cheng Y, Ren X, Hait WN, Yang JM. Therapeutic targeting of autophagy in disease: biology and pharmacology. Pharmacol Rev. 2013;65(4):1162-97.

8. El-Khattouti A, Selimovic D, Haikel Y, Hassan M. Crosstalk between apoptosis and autophagy: molecular mechanisms and therapeutic strategies in cancer. J Cell Death. 2013;6:37-55.

9. Zhou Y, Rucker EB 3rd, Zhou BP. Autophagy regulation in the development and treatment of breast cancer. Acta Biochim Biophys Sin (Shanghai). 2016; 48(1):60-74.

10. Chen N, Karantza V. Autophagy as a therapeutic target in cancer. Cancer Biol Ther. 2011;11(2):157-68.

11. Kimmelman AC. The dynamic nature of autophagy in cancer. Genes Dev. 2011;25(19):1999-2010. 
12. Kim SH, Choi YJ, Kim KY, Yu SN, Seo YK, Chun SS, Noh KT, Suh JT, Ahn SC. Salinomycin simultaneously induces apoptosis and autophagy through generation of reactive oxygen species in osteosarcoma U2OS cells. Biochem Biophys Res Commun. 2016;473(2):607-13.

13. Kim KY, Kim SH, Yu SN, Park SG, Kim YW, Nam HW, An HH, Yu HS, Kim YW, $\mathrm{Ji} \mathrm{JH}$, et al. Lasalocid induces cytotoxic apoptosis and cytoprotective autophagy through reactive oxygen species in human prostate cancer PC-3 cells. Biomed Pharmacother. 2017:88:1016-24.

14. Kim KY, Park KI, Kim SH, Yu SN, Park SG, Kim YW, Seo YK, Ma JY, Ahn SC. Inhibition of Autophagy Promotes Salinomycin-Induced Apoptosis via Reactive Oxygen Species-Mediated PI3K/AKT/mTOR and ERK/p38 MAPK-Dependent Signaling in Human Prostate Cancer Cells. Int J Mol Sci. 2017;18(5).

15. Zhan Y, Gong K, Chen C, Wang H, Li W. P38 MAP kinase functions as a switch in MS-275-induced reactive oxygen species-dependent autophagy and apoptosis in human colon cancer cells. Free Radic Biol Med. 2012;53(3):532-43.

16. Seo JY, Lim SS, Park J, Lim JS, Kim HJ, Kang HJ, Yoon Park JH, Kim JS. Protection by Chrysanthemum zawadskii extract from liver damage of mice caused by carbon tetrachloride is maybe mediated by modulation of $Q R$ activity. Nutr Res Pract. 2010;4(2):93-8.

17. Sassi AB, Harzallah-Skhiri F, Bourgougnon N, Aouni M. Antimicrobial activities of four Tunisian Chrysanthemum species. Indian J Med Res. 2008; 127(2):183-92.

18. Liu Q, Liu H, Yuan Z, Wei D, Ye Y. Evaluation of antioxidant activity of chrysanthemum extracts and tea beverages by gold nanoparticles-based assay. Colloids Surf B Biointerfaces. 2012;92:348-52.

19. He J, Chen F, Chen S, Lv G, Deng Y, Fang W, Liu Z, Guan Z, He C. Chrysanthemum leaf epidermal surface morphology and antioxidant and defense enzyme activity in response to aphid infestation. J Plant Physiol. 2011;168(7):687-93.

20. Kim SJ, Cho HI, Kim SJ, Park JH, Kim JS, Kim YH, Lee SK, Kwak JH, Lee SM. Protective effect of linarin against D-galactosamine and lipopolysaccharideinduced fulminant hepatic failure. Eur J Pharmacol. 2014;738:66-73.

21. Zhen ZG, Ren SH, Ji HM, Ma JH, Ding XM, Feng FQ, Chen SL, Zou P, Ren JR, Jia L. Linarin suppresses glioma through inhibition of NF-kappaB/p65 and up-regulating p53 expression in vitro and in vivo. Biomed Pharmacother. 2017:95:363-74

22. Chen X, Zhang S, Xuan Z, Ge D, Chen X, Zhang J, Wang Q, Wu Y, Liu B. The Phenolic Fraction of Mentha haplocalyx and Its Constituent Linarin Ameliorate Inflammatory Response through Inactivation of NF-kappaB and MAPKs in Lipopolysaccharide-Induced RAW264.7 Cells. Molecules. 2017;22(5).

23. Yang PF, Feng ZM, Yang YN, Jiang JS, Zhang PC. Neuroprotective Caffeoylquinic acid derivatives from the flowers of Chrysanthemum morifolium. J Nat Prod. 2017;80(4):1028-33.

24. Qin $\mathrm{S}$, Wen $\mathrm{X}$. simultaneous determination of 6 active components in Chrysanthemum morifolium by HPLC. Zhongguo Zhong Yao Za Zhi. 2011; 36(11):1474-7.

25. Kongara S, Karantza V. The interplay between autophagy and ROS in tumorigenesis. Front Oncol. 2012;2:171.

26. Zhang T, Li Y, Park KA, Byun HS, Won M, Jeon J, Lee Y, Seok JH, Choi SW, Lee $\mathrm{SH}$, et al. Cucurbitacin induces autophagy through mitochondrial ROS production which counteracts to limit caspase-dependent apoptosis. Autophagy. 2012;8(4):559-76.

27. Park MJ, Song JH, Shon MS, Kim HO, Kwon OJ, Roh SS, Kim CY, Kim GN. Anti-Adipogenic effects of ethanol extracts prepared from selected medicinal herbs in 3T3-L1 cells. Prev Nutr Food Sci. 2016;21(3):227-35.

28. Han S, Sung KH, Yim D, Lee S, Lee CK, Ha NJ, Kim K. The effect of linarin on LPS-induced cytokine production and nitric oxide inhibition in murine macrophages cell line RAW264.7. Arch Pharm Res. 2002;25(2):170-7.

29. Wu TY, Khor TO, Saw CL, Loh SC, Chen Al, Lim SS, Park JH, Cai L, Kong AN. Anti-inflammatory/anti-oxidative stress activities and differential regulation of Nrf2-mediated genes by non-polar fractions of tea Chrysanthemum zawadskii and licorice Glycyrrhiza uralensis. AAPS J. 2011;13(1):1-13.

30. Esteve JM, Knecht E. Mechanisms of autophagy and apoptosis: recent developments in breast cancer cells. World J Biol Chem. 2011;2(10):232-8.

31. Kim SH, Kim KY, Yu SN, Park SK, Choi HD, Ji JH, Ahn SC. Autophagy inhibition enhances silibinin-induced apoptosis by regulating reactive oxygen species production in human prostate cancer PC-3 cells. Biochem Biophys Res Commun. 2015:468(1-2):151-6.

32. Ouyang L, Shi Z, Zhao S, Wang FT, Zhou TT, Liu B, Bao JK. Programmed cell death pathways in cancer: a review of apoptosis, autophagy and programmed necrosis. Cell Prolif. 2012;45(6):487-98.
33. Pan X, Zhang X, Sun H, Zhang J, Yan M, Zhang H. Autophagy inhibition promotes 5 -fluorouraci-induced apoptosis by stimulating ROS formation in human non-small cell lung cancer A549 cells. PLoS One. 2013;8(2):e56679.

34. Yuan L, Wei S, Wang J, Liu X. Isoorientin induces apoptosis and autophagy simultaneously by reactive oxygen species (ROS)-related p53, PI3K/Akt, JNK, and p38 signaling pathways in HepG2 cancer cells. J Agric Food Chem. 2014;62(23):5390-400.

35. Miki H, Uehara N, Kimura A, Sasaki T, Yuri T, Yoshizawa K, Tsubura A. Resveratrol induces apoptosis via ROS-triggered autophagy in human colon cancer cells. Int J Oncol. 2012;40(4):1020-8.

36. Hao W, Zhang X, Zhao W, Chen X. Psoralidin induces autophagy through ROS generation which inhibits the proliferation of human lung cancer A549 cells. PeerJ. 2014;2:e555.

\section{Publisher's Note}

Springer Nature remains neutral with regard to jurisdictional claims in published maps and institutional affiliations.

\section{Ready to submit your research? Choose BMC and benefit from:}

- fast, convenient online submission

- thorough peer review by experienced researchers in your field

- rapid publication on acceptance

- support for research data, including large and complex data types

- gold Open Access which fosters wider collaboration and increased citations

- maximum visibility for your research: over $100 \mathrm{M}$ website views per year

At BMC, research is always in progress.

Learn more biomedcentral.com/submissions 